\title{
Growth hormone in neural tissues of the chick embryo
}

\author{
S Harvey, C D M Johnson and E J Sanders
}

Department of Physiology and Perinatal Research Center, University of Alberta, Edmonton, Alberta, Canada T6G 2 H7

(Requests for offprints should be addressed to S Harvey; Email: steve.harvey@ualberta.ca)

\begin{abstract}
Growth hormone (GH) gene expression predominantly occurs in the pituitary gland, although it also occurs in many extrapituitary sites, including the brain. The cellular location and ontogeny of neural GH production is, however, largely unknown. This has therefore been determined during chick embryogenesis.

In chicks, the brain develops from the neural tube at embryonic day (ED) 3. At this age, the divisions of the brain (the telencephalon, diencephalon, mesencephalon, metencephalon and myelencephalon) have intense $\mathrm{GH}$ immunoreactivity (GH-IR) (detected by two polyclonal antibodies and a monoclonal antibody for chicken $\mathrm{GH}$ ). The otic and optic vesicles were also strongly GH immunoreactive, as were the Vth (semi-lunar), VIIth (facial), VIIIth (acoustic) and IXth (glossopharyngeal) nerve ganglia. This GH-IR was specific for $\mathrm{GH}$ and was lost when the antibodies were preabsorbed with recombinant chicken GH. The widespread distribution of GH-IR in the neural tissues of ED 3 embryos was mirrored by the distribution of $\mathrm{GH}$ receptor (GHR)
\end{abstract}

immunoreactivity, detected by an antibody raised against the chicken GHR.

In ED 6/ED 7 embryos, the neural retina of the eye and the epithelial and lens fiber cells were intensely stained for GH-IR, as was Rathke's pouch and the wall of the diencephalon. In contrast, only a few scattered cells were immunoreactive in the surrounding mesoderm. At ED 14, the GH-IR in the brain was restricted to specific tissues and cells. For instance, immunoreactive cells were present in the molecular and pyramidal layers of the cerebral cortex, in the gray matter of the cerebellum, in the choroid plexus, and in the walls of the ventricles.

In summary, GH- and GHR-like proteins are abundant in neural tissues of the chick during the first third of incubation, becoming discretely localized to specific tissues and cells during later incubation. The localization of $\mathrm{GH}$ and GHR in these tissues, prior to the ontogeny of plasma $\mathrm{GH}$, suggests autocrine or paracrine roles for $\mathrm{GH}$ during early embryogenesis.

Journal of Endocrinology (2001) 169, 487-498

\section{Introduction}

It is now well established that the brain is an extrapituitary site of growth hormone $(\mathrm{GH})$ gene expression (see Harvey et al. 1993 for review). Immunological studies have identified GH-like proteins in homogenates of the whole brain, the telencephalon, diencephalon, mesencephalon, metencephalon and myelencephalon, at concentrations greater than those in blood (Hojvat et al. 1982a,b, 1986). The GH concentration is greatest in the amygdala, hippocampus and hypothalamus, although it is $<1 \%$ of that in the pituitary gland. Immunocytochemical studies in rats have also shown that $\mathrm{GH}$ is present in perikarya, fibers and axon terminals in amygdaloid and hypothalamic nuclei (Lechan et al. 1981, 1983). GH immunoreactivity is also present in preoptic hypothalamic cells in the brain of fish (Hansen \& Hansen 1982, Wright 1986). In birds, GH immunoreactivity has recently been demonstrated in perikarya and fibers in the hippocampus, medial and lateral septum, median eminence and hypothalamus (paraventricular, periventricular, inferior and infundibular nuclei) of turkeys and ring doves (Ramesh et al. 2000). The cellular distribution of $\mathrm{GH}$ within the brain during embryonic or fetal development is, nevertheless, still largely unknown.

Immunoreactive $\mathrm{GH}$ has been measured in extracts of fetal rat brain, in which the GH concentration peaks during gestation and declines towards term, contrary to the ontogenic increase in pituitary GH content (Hojvat et al. 1982b). The appearance of GH in the rat brain, on the tenth day of gestation, occurs prior to that in the pituitary gland, on the twelfth day (Hojvat et al. 1982b). The abundance and/or cellular distribution of GH within the brain is thus likely to change during ontogeny. This possibility was therefore assessed in the present study, in which the localization of $\mathrm{GH}$ in the brain and other neural tissues has been determined in chick embryos before and after the differentiation of pituitary somatotrophs. 


\section{Materials and Methods}

\section{Tissues}

Fertile White Leghorn chicken eggs from the University of Alberta Poultry Unit were incubated at $37.5{ }^{\circ} \mathrm{C}$ in humidified air (Hamburger \& Hamilton 1951). The eggs were turned one quarter of a revolution each day during the 21-day incubation period. Whole chick embryos at embryonic day (ED) 3, 6 and 7 were dissected into phosphate-buffered saline (PBS, $\mathrm{pH} 7 \cdot 4$ ) prior to fixation. Older embryos, at 14 and 19 days of incubation, were killed by decapitation and the heads were similarly collected into PBS. These ages were selected to determine the ontogenic appearance of neural GH. The animal handling was approved by the University of Alberta Health Science Animal Welfare Committee.

\section{Immunocytochemistry}

Tissues were fixed in freshly prepared paraformaldehyde $(4 \% \mathrm{w} / \mathrm{v})$ (Sigma, Mississauga, Ontario, Canada) or Bouin's fixative overnight at $4{ }^{\circ} \mathrm{C}$. Tissues were then dehydrated in a graded series of alcohol (50\%, 15-30 min; 70\%, 30-60 min; 95\%, 30-120 min) and cleared with Hemo-de (Fisher Scientific, Edmonton, Alberta, Canada) for $30 \mathrm{~min}$. Tissues were then infiltrated with paraffin wax for $24-48 \mathrm{~h}$ at $60{ }^{\circ} \mathrm{C}$, under normal atmospheric pressure. Serial transverse $(4-8 \mu \mathrm{m})$ sections were taken using a microtome and were mounted onto charged slides (Fisher Scientific). Immunocytochemical staining was performed with commercial reagents (Vector Laboratories, Burlingame, CA, USA; Sigma) using the avidin-biotinperoxidase (ABC) (Hsu et al. 1981) or the alkaline phosphatase, anti-alkaline phosphatase (APAAP) (Sternberger 1979) method. Sections were incubated with specific polyclonal antisera raised in rabbits against native chicken (c) GH (acGH-1: Harvey \& Scanes 1977) or recombinant cGH ( $\alpha c G H-2$ : Porter et al. 1995). Both of these antibodies were diluted 1:4000 in PBS or in $1-5 \%$ normal goat serum (NGS) overnight, at room temperature. A mouse monoclonal antiserum raised against glycosylated chicken growth hormone (1H7: Berghman et al. 1987) was also used at 1:1000, diluted in NGS or PBS. After incubation, the slides were washed three times for $15 \mathrm{~min}$ in PBS. Sections were then incubated for $1 \mathrm{~h}$ at room temperature in biotinylated goat anti-rabbit immunoglobulin $G(\operatorname{Ig} G)$ (Sigma, 1:500) or in a biotinylated anti-mouse $\operatorname{IgG}$ (Sigma, 1:500). The slides were then washed in PBS and incubated in $\mathrm{ABC}$ reagent for $1 \mathrm{~h}$ at room temperature and washed in PBS. Staining was visualized using the chromogenic substrate diaminobenzidine tetrahydrochloride (DAB) (Sigma), which resulted in a brown coloration. In some instances, nickel chloride (Sigma) was added to the DAB, resulting in a black precipitate. The specificity of staining was determined by preabsorbing the $\mathrm{GH}$ antisera with recombinant cGH (Amgen, Thousand Oaks, CA, USA; $1 \mathrm{mg} / \mathrm{ml}$ ) for $1 \mathrm{~h}$ prior to section incubation. Non-specific staining was determined by replacing $\mathrm{GH}$ antisera with pre-immune rabbit serum (NRS). Other controls included the omission of the secondary antibody and the replacement of the primary antibody with PBS.

The APAAP technique involved the use of a secondary antibody conjugated with alkaline-phosphatase (Sigma). After incubation with the secondary antibody, the sections were washed in PBS and incubated with 10\% APAAP, for $1 \mathrm{~h}$ at room temperature. The sections were then washed and Fast Red TR/Napthol As-MX (Sigma) was applied to tissue sections until optimum color development.

$\mathrm{GH}$ receptor (GHR) immunoreactivity was detected using a polyclonal antibody (at a concentration of 1:400) raised in rabbits against recombinant chicken GH binding protein (rcGHBP) (Huang et al. 1993, Hull et al. 1996), using the $\mathrm{ABC}$ technique, as detailed above. The specificity of staining was demonstrated by replacement of the primary antibody with non-immune rabbit serum (NRS) or PBS. In previous studies (Hull et al. 1996), the specificity of staining was also established by the ability of excess rcGHBP or homogenates of COS cells expressing cGHBP to completely block its immunostaining. Since cGHBP is the extracellular domain of the cGHR, the primary antibody recognizes GHR/GHBP immunoreactivity.

Neural structures were identified according to Romanoff (1960), and Kuenzel \& van Tienhoven (1982).

\section{Results}

\section{Immunocytochemistry}

At ED 3, the neural tube develops anteriorly to give rise to the brain. In birds, the divisions of the brain, anteriorly to posteriorly, are the telencephalon (which develops into the cerebral hemispheres), the diencephalon or thalamus and hypothalamus, the mesencephalon or mid-brain, the metencephalon or cerebellum, and the myelencephalon or medulla oblongata. At ED 3, all of these divisions are present and the lumen of each division is continuous with the others. At ED 3, all the major divisions of the brain were GH immunoreactive. Fig. 1A shows that the telencephalon is strongly immunoreactive, with GH immunoreactivity in all cells lining the lumen. This staining is present in cytoplasmic and nuclear or perinuclear compartments of most cells. The specificity of this staining is indicated by its loss after the primary antisera had been preincubated with recombinant cGH (Fig. 1B). The replacement of the antisera with NRS similarly failed to stain adjacent sections (data not shown). The otic vesicle, which develops into the ear, was also strongly $\mathrm{GH}$ immunoreactive (Fig. 1C). This immunoreactivity was again lost following preabsorption of the primary antisera 

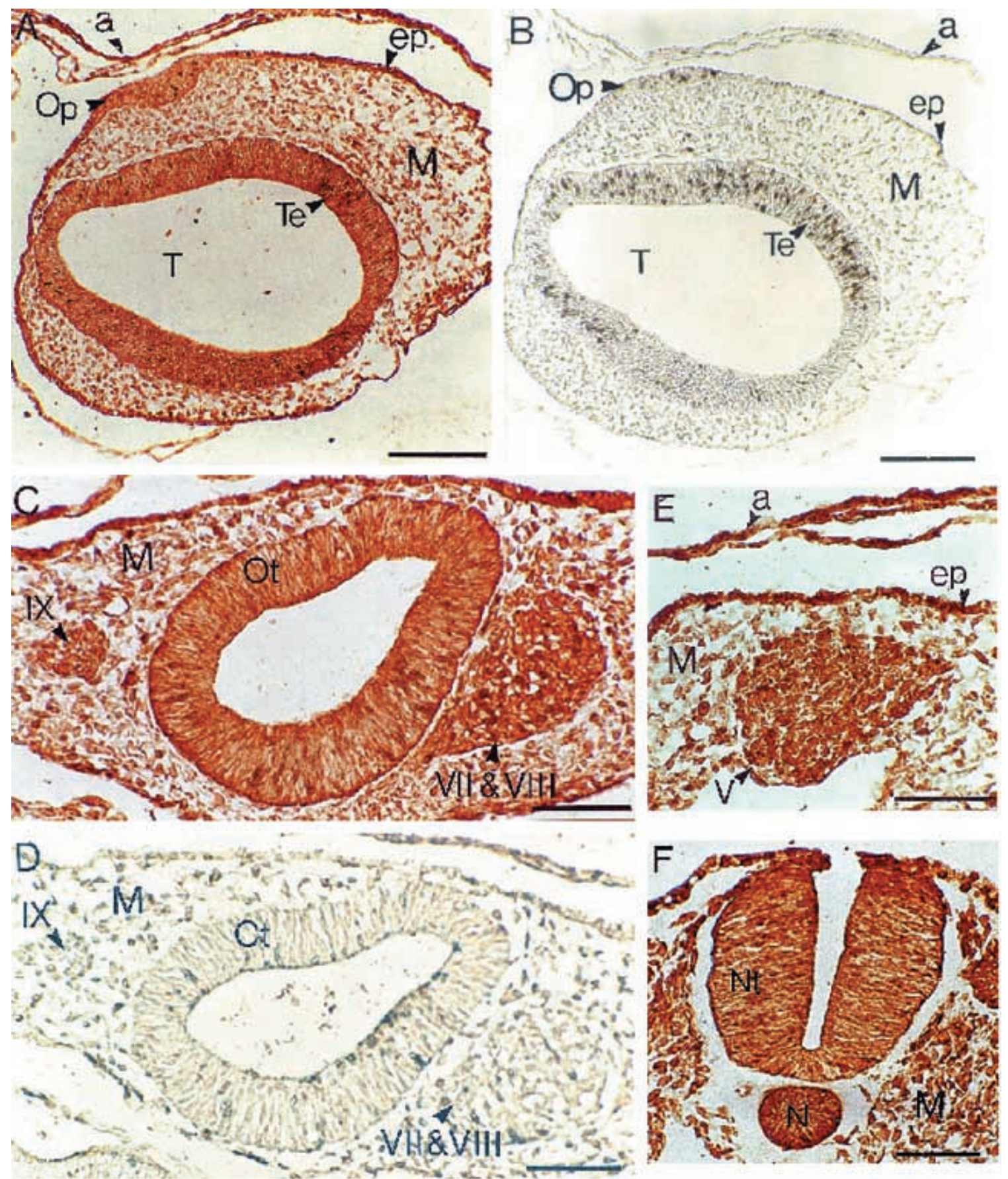

Figure $1 \mathrm{GH}$ immunoreactivity in neural tissues of the ED 3 embryo. (A) Transverse section through the telencephalon (Te). The wall of the telencephalon is strongly stained for $\mathrm{GH}$. The olfactory pit $(\mathrm{Op})$ is also GH immunoreactive and is of a similar staining intensity to the telencephalon. The amnion (a), mesoderm (M), surrounding the brain and epidermis (ep) of the head are also immunoreactive. T, teleocoel. Bar $=120 \mu \mathrm{m}$. (B) $\mathrm{GH}$ immunoreactivity is reduced in the telencephalon, olfactory pit, mesoderm and epidermis when the primary antibody $(\alpha \mathrm{GH} 1)$ is preabsorbed with recombinant cGH. Note the higher background contrast necessary for visualization of the tissue section. (C) The otic vesicle (Ot) and associated nerve ganglia show strong GH immunoreactivity. IX, 9th cranial nerve (glossopharyngeal), VII \& VIII, 7th and 8th cranial nerves which are closely associated with each other. Bar $=60 \mu \mathrm{m}$. (D) Preabsorption of the primary antibody abolishes staining; this section shows the same area as $(\mathrm{C})$. (E) The semilunar nerve ganglion or Vth cranial nerve $(\mathrm{V})$ is strongly GH immunoreactive. Bar $=60 \mu \mathrm{m}$. (F) The neural tube (Nt) towards the posterior of the embryo and the notochord $(\mathrm{N})$ are strongly $\mathrm{GH}$ immunoreactive. Bar $=60 \mu \mathrm{m}$. 

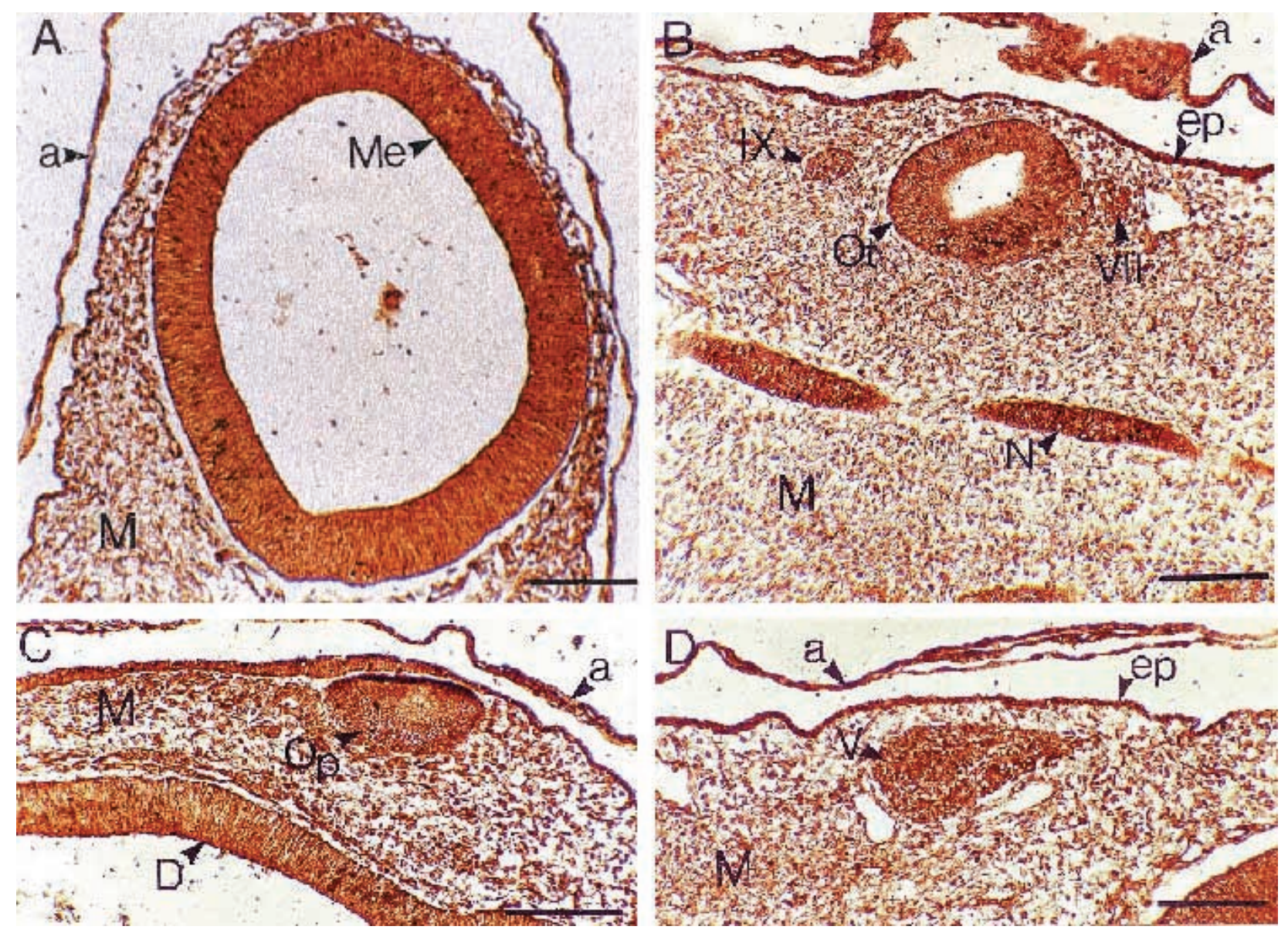

Figure 2 GHR immunoreactivity in neural tissues of the ED 3 embryo. GHR immunoreactivity was observed in all major divisions of the brain. The mesencephalon (Me) is shown as a representation in (A). a, amnion; $M$, mesoderm. (B) GHR immunoreactivity is observed in the otic vesicle $(\mathrm{Ot})$ and associated nerves (VII, facial/acoustic ganglia; IX, glossopharyngeal nerve). Also shown is the notochord (N), amnion (a), epidermis (ep) and mesoderm (M). (C) GHR immunoreactivity in the optic vesicle (Op) and diencephalon (D). (D) This section shows that the sublunar ganglion (V) is strongly GHR immunoreactive. Also shown are the amnion (a), epidermis (ep) and mesoderm (M). PBS or NRS controls were used to replace the GHR antibody and did not result in staining (data not shown). Bar $=100 \mu \mathrm{m}$.

with recombinant cGH (Fig. 1D). Several cranial ganglia were also GH immunoreactive. The Vth (semilunar) nerve, VIIth (facial) nerve, VIIIth (acoustic) nerve and the IXth (glossopharyngeal) nerve ganglia were all strongly GH immunoreactive (Fig. 1E). The neural tube, posteriorly, was also GH immunoreactive, with an intensity of staining comparable with the anterior neural tube (Fig. 1F). Identical results were observed when $\alpha \mathrm{cGH}-2$ or $1 \mathrm{H} 7$ was used as the primary antibody (data not shown).

The widespread distribution of $\mathrm{GH}$ immunoreactivity in the neural tissues of the ED 3 embryos was mirrored by the cellular and subcellular distribution of GHR immunoreactivity (Fig. 2). The mesencephalon (Fig. 2A) is characteristic of the staining of other brain regions. Strong GHR staining was seen in the wall of the mesencephalon and the surrounding mesodermal tissue. The otic vesicle (Fig. 2B) and the associated ganglia (the facial/acoustic ganglia) were also strongly GHR immunoreactive. The optic vesicle, which develops into the eye, had intense GHR immunoreactivity (Fig. 2C). The Vth cranial ganglia and the surrounding mesoderm similarly contained intense GHR immunoreactivity (Fig. 2D). The replacement of the primary antisera with NRS or PBS did not result in any staining (data not shown).

In ED 6 embryos, the neural retina of the eye was strongly GH immunoreactive (not shown). The epithelial and lens fiber cells were intensely stained for GH immunoreactivity (Fig. 3A). This staining was lost following the preabsorption of the primary antibody with recombinant cGH (Fig. 3B). The cytoplasm of the cortical lens fiber cells was less immunoreactive than the nuclei (Fig. 3A).

By 7 days of incubation (stage 31), GH immunoreactivity was still abundantly present in the optic cup (Fig. 4A). The neural retina was intensely and evenly stained for 

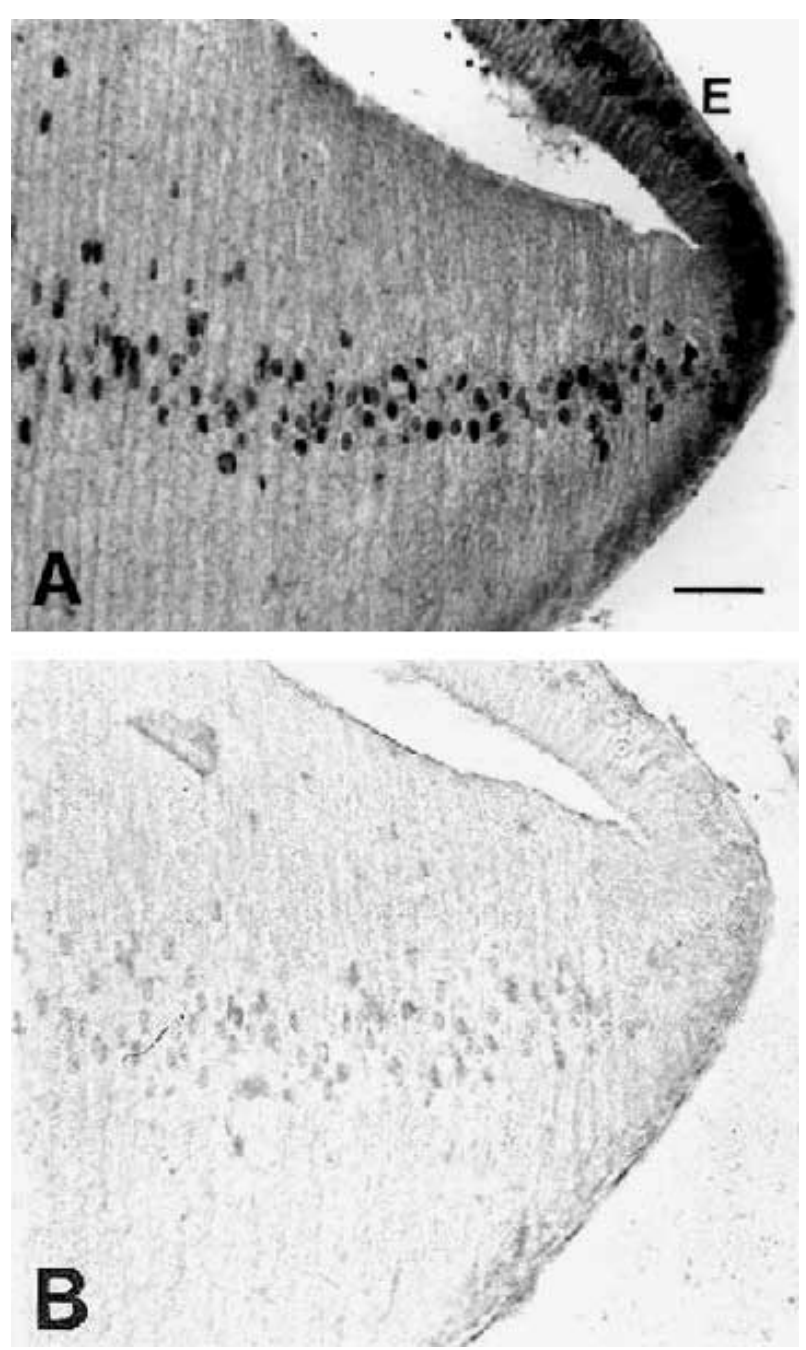

Figure $3 \mathrm{GH}$ immunoreactivity in the lens of the ED 6 embryo. (A) The lens epithelium (E) is strongly $\mathrm{GH}$ immunoreactive in both cytoplasm and nuclei. The lens fiber cells show immunoreactivity primarily in their nuclei. (B) Preabsorption of the antibody with recombinant $\mathrm{CGH}$ abolishes the reactivity. Bar $=200 \mu \mathrm{m}$.

GH (Fig. 4B), although the mesodermal layer lying above the pigmented retina was much less immunoreactive, with only a few cells staining for GH. The epidermis of the head was also GH immunoreactive (Fig. 4B). The GH immunoreactivity in the eye neural retina was primarily nuclear (Fig. 4D) and was lost following preabsorption of the antibody with recombinant cGH (Fig. 4C).

The diencephalon and Rathke's pouch of the ED 7 embryo were intensely stained for GH-like proteins, particularly in nuclear or perinuclear compartments (Fig. $4 \mathrm{E})$, whereas only a few scattered cells in the surrounding mesoderm were lightly stained (Fig. 4E and Fig. 5A). The otic vesicle and cells in the acoustic (VIIIth nerve), facial/acoustic (VIIth and VIIIth nerves) and semilunar (Vth) ganglia were also strongly immunoreactive (Fig. $5 B)$.

In ED 14 embryos, the brain was still very GH immunoreactive (Fig. 6), although the immunoreactivity was not widespread and was restricted to specific tissues and cells. For instance, most cells in the choroid plexus (a circumventricular organ) stained particularly strongly for GH (Fig. 6A), as did cells in the pineal stalk and pineal gland (data not shown). This staining was lost when the primary antibody was preabsorbed with recombinant cGH (Fig. 6B). Within the cerebral cortex, many cells had GH immunoreactivity within the molecular and pyramidal layers (Fig. 6C). This staining was again lost following preabsorption of the primary antibody with recombinant cGH (Fig. 6D). Because of their position and morphology, it was presumed that many of the immunoreactive cells in the gray matter of the cerebral cortex were probably astrocytes (Fig. 7A). Numerous smaller cells were also strongly stained for GH (Fig. 7B). This staining was lost following the preabsorption of the primary antibody with recombinant $\mathrm{CGH}$ (Fig. 7F). Large pyramidal neurons were also intensely stained for GH (Fig. 7C). Large cells from the pyramidal neuron layer showed very dense nuclear GH immunoreactivity and lesser cytoplasmic staining (Fig. 7D). Nerve tract fibres located in the white matter of the cerebral cortex also contained GH immunoreactivity (Fig. 7E).

At ED 19 (stage 45), the ependymal cells lining the ventricles were immunoreactive, including the subtrochlear organ, which was intensely stained for GH (Fig. 8B). Preincubation of the primary GH antibody with recombinant cGH resulted in a complete loss of staining (data not shown).

Within the cerebellum of the ED 19 embryo, the cells of the gray matter were intensely stained for $\mathrm{GH}$, using $\alpha \mathrm{GH} 1$ as the primary antibody. Identical results were seen when $\alpha_{c}$ GH-2 was used as the primary antibody (data not shown). The Purkinje cells, located between the gray and molecular layers of the cerebellum, were particularly GH immunoreactive (Fig. 8A). The molecular layer and the white matter did not appear to be as strongly stained (Fig. 8A). Preincubation of the primary antibody with recombinant $\mathrm{cGH}$ completely abolished staining in the cerebellum (data not shown).

\section{Discussion}

The possibility that GH may be present in neural tissues of the chick embryo was first indicated by its presence in the neural tube (spinal cord) of ED3 embryos (Harvey et al. 2000b), as confirmed in the present study (Fig. 1F). The results of these studies also show, for the first time, that GH immunoreactivity is present in discrete cells in the developing brain, and is present in otic and optic tissues. 


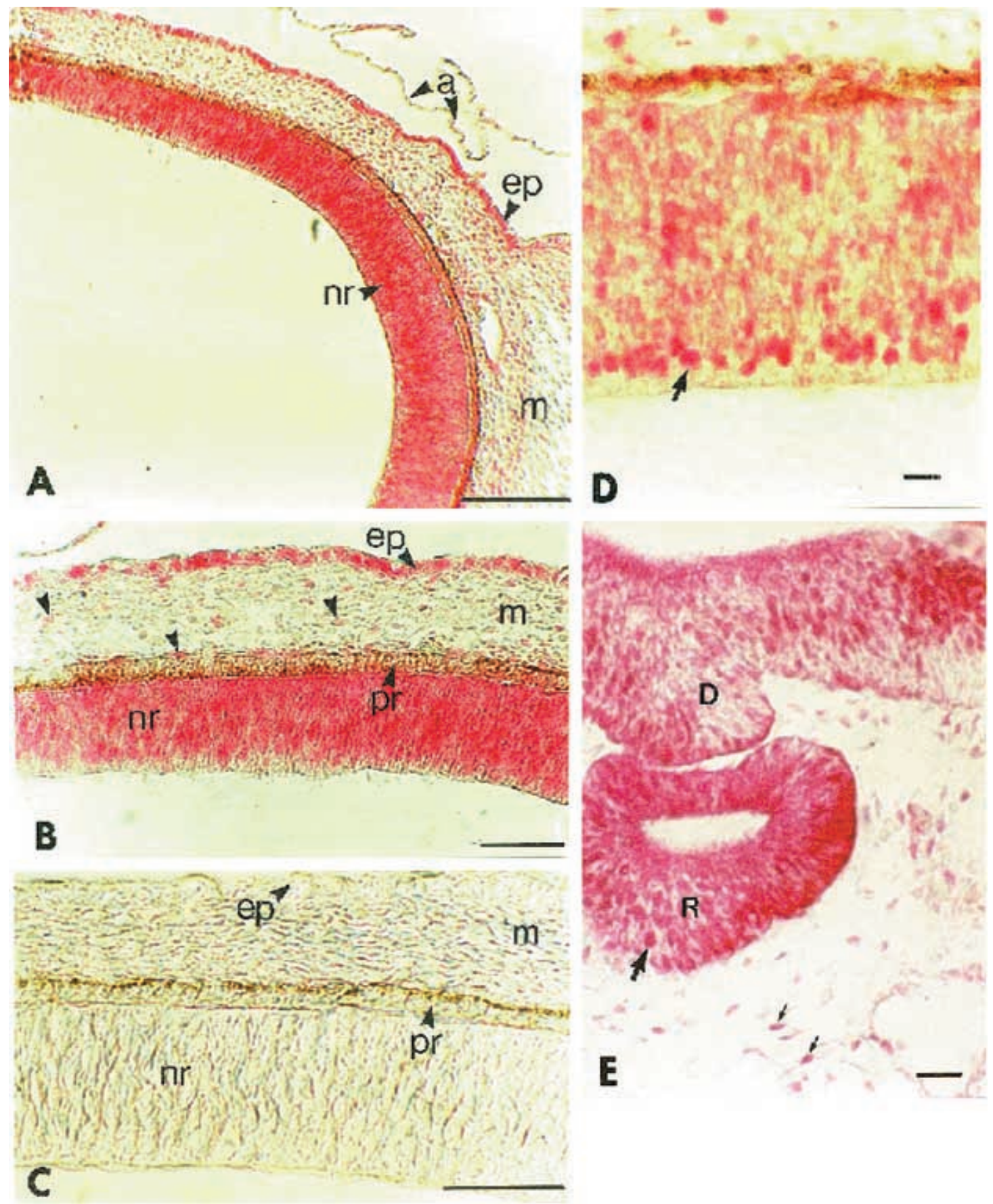

Figure $4 \mathrm{GH}$ immunoreactivity in the ED 7 eye. (A) Transverse section through the head of a 7-day embryo showing part of the developing eye. The neural retina $(\mathrm{nr})$ is very intensely stained but the mesoderm $(\mathrm{m})$ which lies above the neural retina is much less immunoreactive, suggesting that staining is specific. The head epidermis (ep) was also strongly immunoreactive. a, amnion. (B) High power magnification of the neural retina which lies below the pigmented retina (pr). Notice that scattered cells within the mesoderm $(\mathrm{m})$ were lightly stained (arrows). (C) The immunoreactive staining was completely abolished when the primary antibody $(\alpha \mathrm{GH} 1)$ was preincubated with recombinant $\mathrm{cGH}$. (D) Higher magnification of the neural retina, showing nuclear staining (arrow). (E) GH immunoreactivity in Rathke's pouch (R) and diencephalon (D) of the ED 7 chick embryo showing intense nuclear staining (large arrow). Scattered cells in the surrounding mesenchyme are also immunoreactive (small arrows). Bars $=50 \mu \mathrm{m}$. 


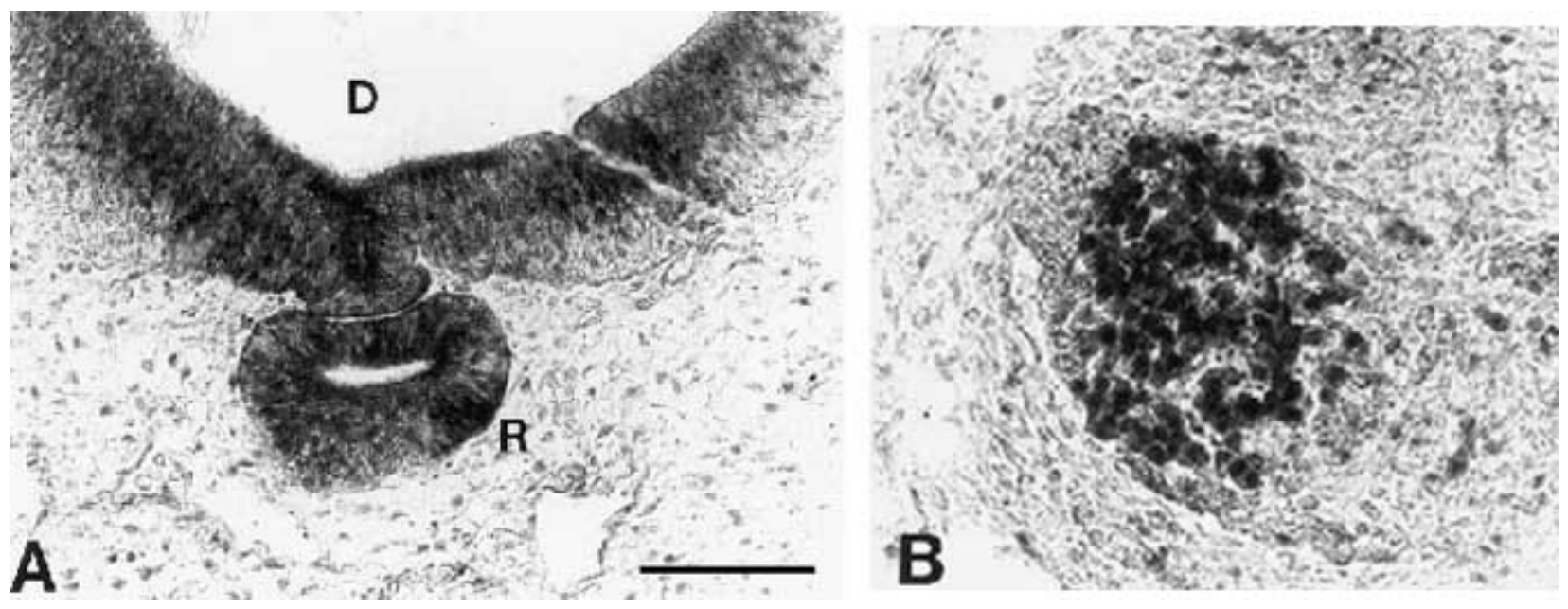

Figure $5 \mathrm{GH}$ immunoreactivity in the ED 7 brain and nerve ganglia. (A) $\mathrm{GH}$ reactivity with $\alpha \mathrm{GH} 1$ was found in the wall of the diencephalon (D) and in Rathke's pouch (R). (B) The semilunar ganglion was intensely labeled in comparison with surrounding mesoderm. Preabsorption of the primary antiserum $(\alpha \mathrm{GH} 1)$ with recombinant $\mathrm{CGH}$ or its replacement with NRS failed to result in any staining (data not shown). Bar $=40 \mu \mathrm{m}$.

In the brain, $\mathrm{GH}$ immunoreactivity is clearly abundant and widespread during the first third of incubation, becoming discretely localized in specific neuronal cells in the last third of incubation. Although GH immunoreactivity is found in many cells in early embryogenesis, it is specifically located in the perikarya of pyramidal neurons within the cerebral cortex and in Purkinje cells of the cerebellum in ED 19 embryos. The distribution of GH immunoreactivity in the embryonic brain prior to hatch therefore differs from its predominantly hypothalamic location in adult turkeys and ring doves (Ramesh et al. 2000). This could reflect a species difference or difference due to ontogeny.

The GH immunoreactivity in neural tissues of the chick embryo is likely to reflect the distribution of GH rather than GH-like proteins, since it was detected by three different chicken GH antibodies, was ontogenically restricted to specific cells and could be competitively blocked by preabsorption of the primary antibodies with recombinant GH. Furthermore, the distribution of GH immunoreactivity in the embryo was very different from the distribution of prolactin, luteinizing hormone, and thyrotropin immunoreactivity (Murphy et al. 2000). Peripheral tissues of early chick embryos have also been shown to react similarly to the same GH antibodies, and this reactivity is associated with proteins in extracts of the head and body that are identical in size to pituitary $\mathrm{GH}$ (Harvey et al. 2000a,b). The GH immunoreactivity in neural tissues of the chick embryo are also likely to reflect the expression of the GH gene, since GH mRNA has been detected by RT-PCR in the heads, bodies and eyes of early chick embryos (Harvey et al. 2000b). Moreover, although neural $\mathrm{GH}$ in the rat brain differs from pituitary
GH in amino acid sequence (Hojvat et al. 1982a), neural $\mathrm{GH}$ in adult chickens is identical to pituitary $\mathrm{GH}$ in nucleotide sequence (Render et al. 1995). This immunoreactivity is unlikely to reflect the sequestration of pituitary $\mathrm{GH}$, since it occurs prior to the ontogeny of morphologically identifiable pituitary somatotrophs (at day 12-14; Malamed et al. 1993) and pituitary cells that secrete GH (at day 16; Porter 1997).

GH immunoreactive cells were abundantly present in Rathke's pouch at ED 7 (Fig. 4E and Fig. 5A), but it is significant that most of the reactivity was associated with nuclear or perinuclear compartments. In contrast, $\mathrm{GH}$ immunoreactivity in somatotrophs identified by their morphological characteristics is restricted to cytoplasmic secretory granules and is present in only a small population of pituitary cells (Malamed et al. 1993, Porter 1997). The abundant GH immunoreactive cells in Rathke's pouch (the primordial pituitary) thus differ from the fully differentiated pituitary somatotrophs that appear in the last third of incubation.

The nuclear or perinuclear localization of GH in many neural cells of the chick embryo is consistent with its localization in many peripheral tissues (Harvey et al. 2000b). GH immunoreactivity has also been demonstrated in nuclear compartments in mammalian studies (e.g. Rezvani et al. 1973, Bonifacino et al. 1983). A nuclear localization of GH within GH-producing cells may occur if it escapes packaging in the Golgi following its synthesis, and this is particularly likely in rapidly growing or differentiating embryonic cells, as occurs in rapidly proliferating or neoplastic cells (Mol et al. 1996, Lincoln et al. 1998). A nuclear or perinuclear localization of GH may also reflect the subcellular distribution of the GHR, since it is well 

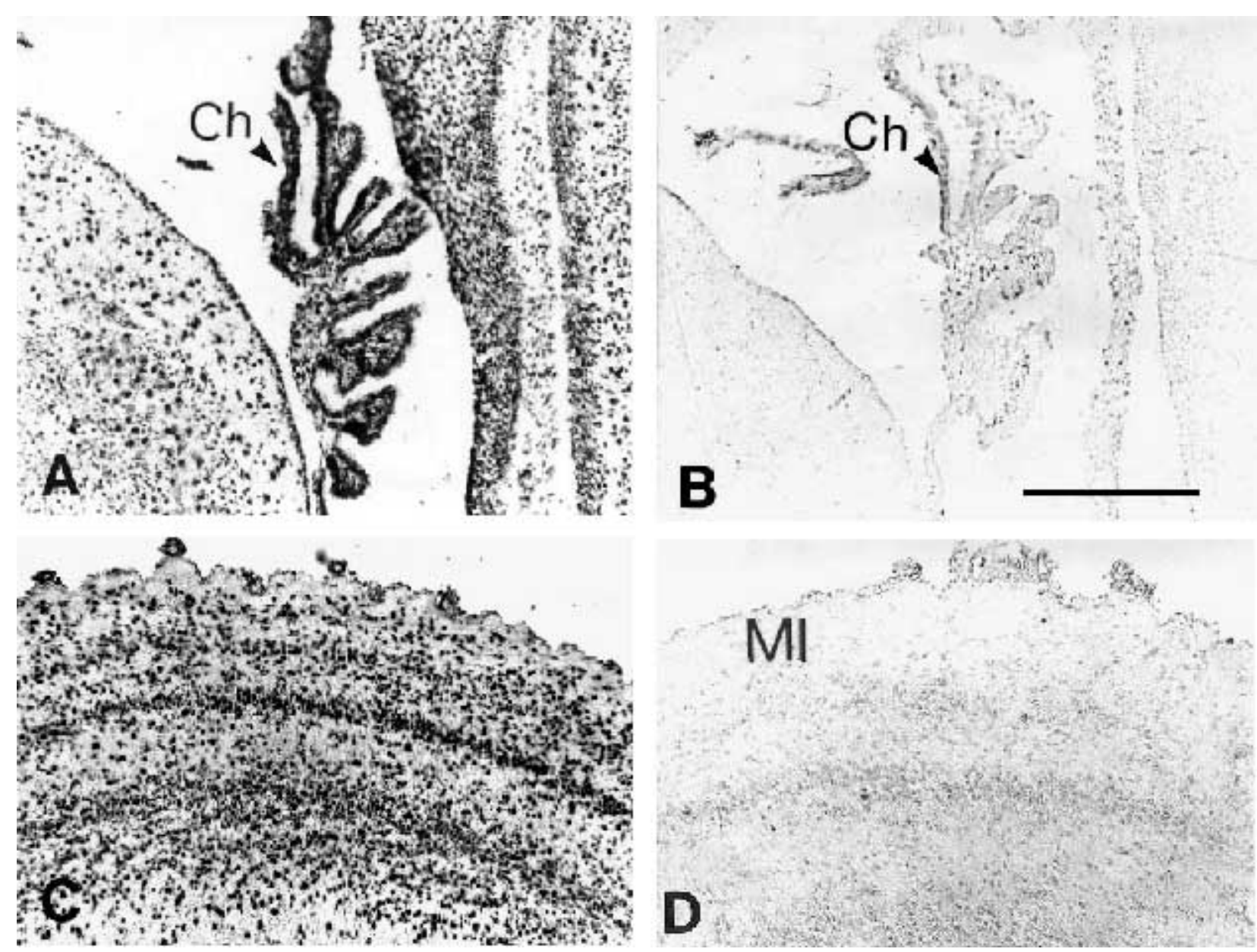

Figure $6 \mathrm{GH}$ immunoreactivity in the choroid plexus and the cerebral cortex of the ED 14 chick embryo. (A) The choroid plexus (Ch) is strongly immunoreactive. (B) Staining is abolished after preabsorption of the primary antibody $(\alpha \mathrm{GH} 1)$ with recombinant cGH. (C) Various layers of the gray matter of the cerebral cortex are reactive. At this stage of development, the cortex is not fully differentiated. The outer molecular layer (M1) is characterized by fewer cells and fibers than the inner pyramidal layer. (D) Preabsorption of $\alpha \mathrm{GH} 1 \mathrm{with}$ recombinant $\mathrm{cGH}$ completely abolished staining in a similar section to (C). Bar $=50 \mu \mathrm{m}$.

established that membrane-bound GH is rapidly internalized to nuclear compartments in target cells (e.g. Lobie et al. 1991, 1994a,b, Fraser \& Harvey 1992).

The early ontogeny of GH in neural tissues of the chick embryo is consistent with the ontogeny of $\mathrm{GH}$ in the rat brain prior to pituitary somatotroph differentiation (Hojvat et al. 1982b) and the appearance of GH mRNA in the head of embryonic trout prior to pituitary differentiation (Yang et al. 1999). This early ontogeny may reflect an earlier expression of Pit-1, since Pit-1 is detectable in the brains of ED 2 chick embryos and Pit-1 is the transcription factor that induces the transcription of the pituitary $\mathrm{GH}$ gene (Harvey et al. 2000a). Indeed, Pit-1 is not present in the brains of adult rats (Emanuelle et al. 1992), but is widespread in the brains of fetal rats (He et al. 1989), prior to the appearance of GH immunoreactive proteins (Hojvat et al. 1982b).
Within the embryonic chick brain, GH immunoreactivity was particularly abundant in the choroid plexus, as in the brains of developing rats (Hojvat et al. 1982a, Lechan et al. 1983) and the brains of adult turkeys and ring doves (Ramesh et al. 2000). It is therefore likely that GH is produced in this tissue, although GH also binds to this circumventricular organ (CVO) in rats (van Houten 1980, Garcia-Aragon et al. 1992), rabbits (Mangurian et al. 1994), sheep (Thornwall et al. 1995) and man (Lai et al. 1991) to facilitate two-way GH transport through the blood-brain barrier. It is therefore of interest that $\mathrm{GH}$ immunoreactivity was also abundant in another CVO, the pineal gland (data not shown), as also observed in adult turkeys (Ramesh et al. 2000). Proteins with GH-like immunoreactivity and physiochemical characteristics have similarly been identified in extracts of the ovine pineal gland (Noteborn et al. 1993). The intense GH 

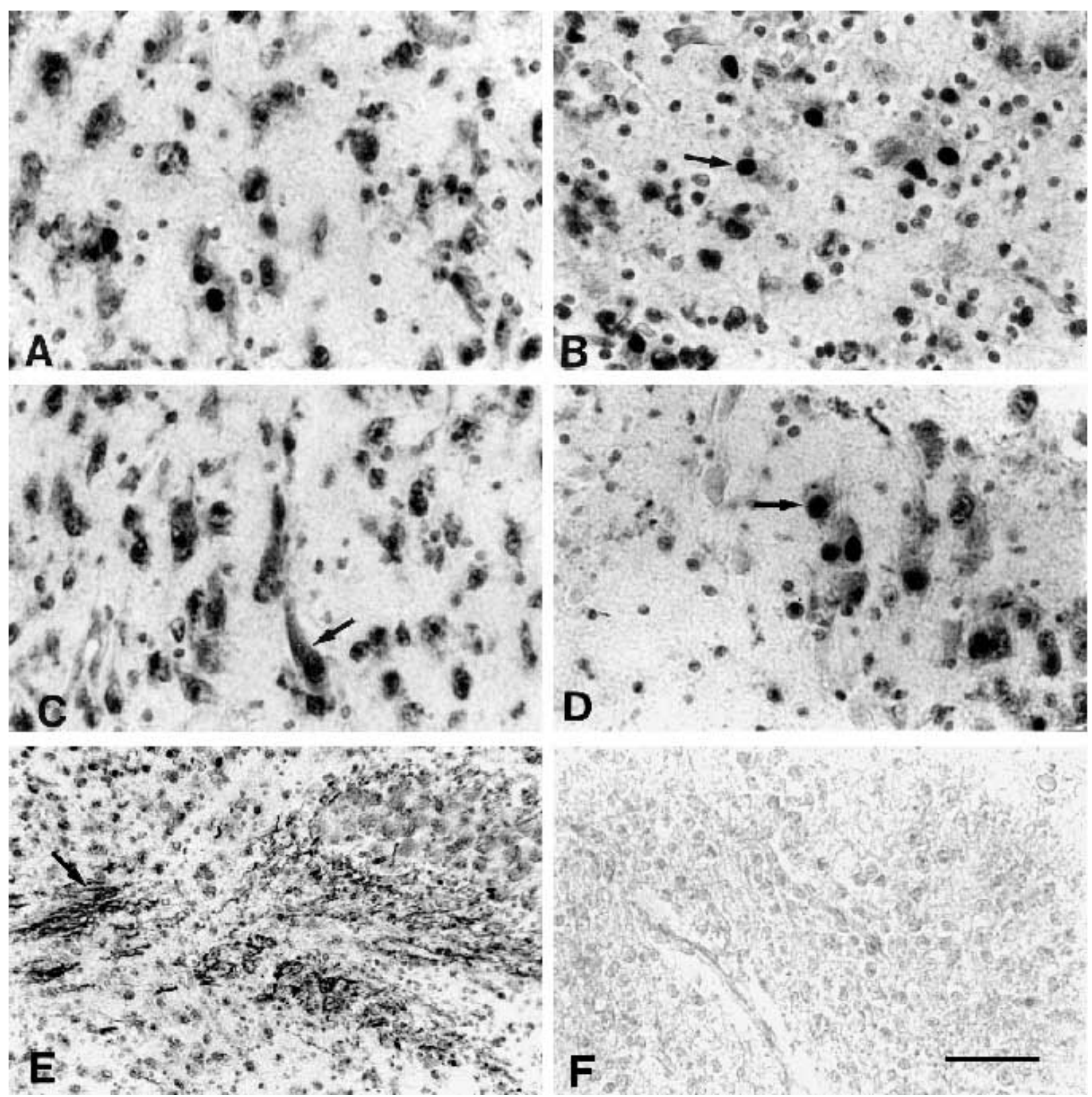

Figure $7 \mathrm{GH}$ immunoreactivity in the cerebral cortex of the ED 14 chick embryo. (A) Immunoreactive cells from the gray matter of the cerebral cortex (possibly astrocytes). (B) Small and densely packed cells from the white matter showing intense reactivity (arrow). (C) Immunoreactive cell bodies of large pyramidal neurons (arrow), which sent their axons towards the white matter. (D) Dense nuclear labeling (arrow) in pyramidal cells. (E) Nerve tract fibers (arrow) from the white matter are immunoreactive. (F) A region similar to that shown in (B), showing that preabsorption of $\alpha \mathrm{GH} 1$ with recombinant $\mathrm{cGH}$ completely abolished staining. Bar $=10 \mu \mathrm{m}$.

immunoreactivity of these circumventricular organs is also likely to reflect receptor-bound ligand, since the choroid plexus has a greater abundance of GHRs than any other site in the central nervous system (Lai et al. 1991, Lobie et al. 1993). The ependymal cells lining the ventricular system of the rat brain also have intense GHR immunoreactivity (Lobie et al. 1993) and it is therefore not surprising that the subtrochlear organ in the chicken brain (comprised of modified ependymal cells) contained intense GH immunoreactivity (Fig. 8).

Although GH is abundantly present in neural tissues of the chick embryo, it is absent from the circulation of early 


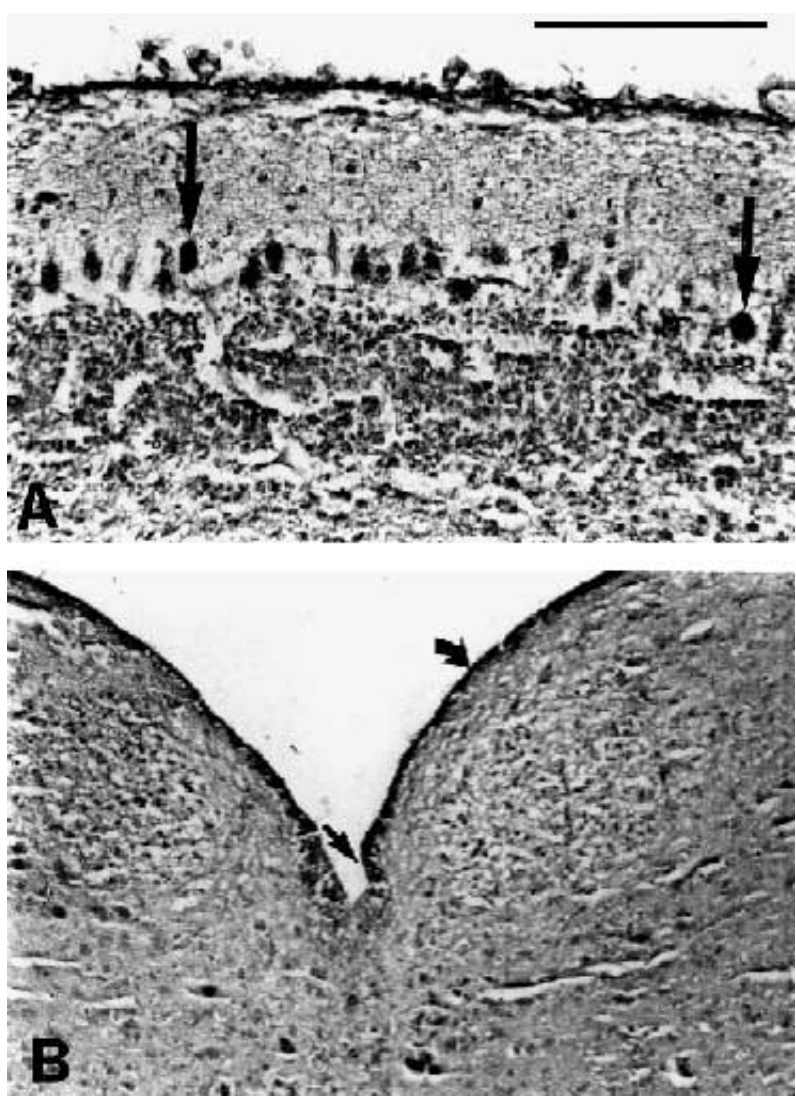

Figure 8 (A) GH immunoreactivity in the cerebellum of the ED 19 embryo. The large Purkinje cells are intensely reactive (arrow). (B) $\mathrm{GH}$ immunoreactivity in the subtrochlear organ (straight arrow) of the ED 19 embryo. This organ consists of modified ependymal cells continuous with the ependymal layer (curved arrow) lining the ventricle, which is also immunoreactive.

embryos (Harvey et al. 1979), indicating that it is not secreted from neural sites. Neural GH is therefore likely to act locally (Nyberg \& Burman 1996). Indeed, the widespread distribution of $\mathrm{GH}$ within the brain of the early chick embryo mirrored the distribution of GHR immunoreactivity. Although the presence of GH binding sites in the central nervous system was first demonstrated in adult chickens (Attardo \& Harvey 1990), the distribution of GHR immunoreactivity in the brain during ontogeny was surprising, since hepatic GHR mRNA was not detectable in chick embryos until ED 15 (Burnside \& Cogburn 1992, Tanaka et al. 1996) and because hepatic membrane binding sites for $\mathrm{GH}$ were not detected until ED 14 (Vanderpooten et al. 1991, 1992). This may reflect the different methodologies used in these studies, although extra-hepatic GHRs are more abundant than hepatic GHRs during early fetal development (Hill 1992), which suggests the liver is not a major $\mathrm{GH}$ target site at this time. Indeed, the central nervous system may be a primary site for GH action during early embryogenesis, since the abundance of neural GHRs increases during ontogeny in rats and declines postnatally, in contrast with the postnatal increase in hepatic and peripheral GHRs (Hasegawa et al. 1993, Lobie et al. 1993).

In addition to the brain and the cranial nerves, GH immunoreactivity and GHR immunoreactivity were also located in the optic and otic vesicles. In the eye, the neural retina had intense nuclear GH immunoreactivity, whereas this was absent from the overlying mesenchymal layer (Fig. 4). This may reflect the abundance of the GHR, since retinal ganglion cells in rats contain intense GHR immunoreactivity, whereas the inner plexiform layer of the retina has only moderate to weak GHR immunoreactivity (Lobie et al. 1993). The localization of GH and GHR in the optic and otic vesicles (Figs 1 and 2) indicates that GH may have roles in the development of the ear and the eye. This is, however, the first demonstration of GH in these tissues and its putative roles are therefore uncertain. It is, nevertheless, of interest that insulin-like growth factor-I (IGF-I) is also located in the neural retina of chicks, since IGF-I affects lens differentiation (Wride 1996) and is inducible by GH in other tissues (Radecki \& Scanes 1997). It is also of interest that somatostatin, which regulates the release of pituitary GH (Harvey et al. 1993), is also present in the retina of embryonic and adult chickens (Ellis et al. 1983) and may thus be involved in the local production or release of $\mathrm{GH}$ within the eye.

In summary, the results of this study clearly establish that GH and GHR are present in the neural tissues of chick embryos prior to and after the differentiation of pituitary somatotrophs. It is therefore likely that $\mathrm{GH}$ participates in the growth and differentiation of the chick embryonic brain, cranial nerves, eye and ear. The colocalization of GH and GHR in these tissues during early embryogenesis, prior to the ontogeny of plasma $\mathrm{GH}$, indicates that $\mathrm{GH}$ is likely to act as an autocrine or paracrine hormone in these extrapituitary sites.

\section{Acknowledgements}

The authors would like to thank Dr T E Porter, Dr J Burnside and Dr L R Berghman for the gift of antibodies, and the Natural Science and Engineering Research Council of Canada and the Medical Research Council of Canada for financial support.

\section{References}

Attardo D \& Harvey S 1990 Growth hormone-binding sites in chicken hypothalamus. Journal of Molecular Endocrinology 4 23-29.

Berghman LR, Lens P, Decuypere E, Kuhn ER \& Vandesande F 1987 Glycosylated chicken growth hormone. General and Comparative Endocrinology 68 408-414.

Bonifacino JS, Roguin LP \& Paladini AC 1983 Formation of complexes between ${ }^{125}$ I-labeled human or bovine somatotropins and binding proteins in vivo in rat liver and kidney. Biochemical Journal 214 121-132. 
Burnside J \& Cogburn LA 1992 Developmental expression of hepatic growth hormone receptor and insulin-like growth factor-I mRNA in the chicken. Molecular and Cellular Endocrinology 8 91-96.

Ellis JP, Sullivan JM \& Rana MW 1983 Somatostatin-like immunoreactivity in the retinae of adult and embryonic chickens. Proceedings of the Society for Experimental Biology and Medicine $\mathbf{1 7 2}$ 463-471.

Emanuelle NV, Jurgens JK, Halloran MM, Tentler JJ, Lawrence AM \& Kelley MR 1992 The rat prolactin gene is expressed in brain tissue: detection of normal and alternatively spliced prolactin messenger RNA. Molecular Endocrinology 6 35-42.

Fraser RA \& Harvey S 1992 Ubiquitous distribution of growth hormone receptor and/or binding proteins in adenohypophyseal tissue. Endocrinology 130 3593-3600.

Garcia-Aragon J, Lobie PE, Muscat GO, Gobius KS, Norstedt G \& Waters MJ 1992 Prenatal expression of the growth hormone $(\mathrm{GH})$ receptor/binding protein in the rat: a role for $\mathrm{GH}$ in embryonic and fetal development? Development 114 868-876.

Hamburger V \& Hamilton HL 1951 A series of normal stages in the development of the chick embryo. Journal of Morphology 88 49-92.

Hansen BL \& Hansen GN 1982 Immunocytochemical demonstration of somatotropin-like and prolactin-like activity in the brain of Calamoichthys calabaricus (Actinopterygii). Cell and Tissue Research $2226615-6627$.

Harvey S \& Scanes CG 1977 Purification and radioimmunoassay of chicken growth hormone. Journal of Endocrinology 73 321-329.

Harvey S, Davison DF \& Chadwick A 1979 Ontogeny of growth hormone and prolactin secretion in domestic fowl, Gallus domesticus. General and Comparative Endocrinology 59 270-273.

Harvey S, Hull KL \& Fraser RA 1993 Growth hormone: neurocrine and neuroendocrine perspectives. Growth Regulation 3 161-171.

Harvey S, Azumaya Y \& Hull KL 2000a Extrapituitary growth hormone: Pit-1 dependence? Canadian Journal of Physiology and Pharmacology 78 1013-1028.

Harvey S, Johnson CDM \& Sanders EJ $2000 b$ Extrapituitary growth hormone in peripheral tissues of early chick embryos. Journal of Endocrinology 166 489-502.

Hasegawa O, Minami S, Sugihara H \& Wakabayashi I 1993 Developmental expression of the growth hormone receptor gene in the rat hypothalamus. Developmental Brain Research 74 287-290.

He XI, Treacy MN, Simmons DM, Ingraham HA, Swanson LW \& Rosenfeld MG 1989 Expression of a large family of POU domain regulatory genes in mammalian brain development. Nature $\mathbf{3 4 0}$ $35-42$.

Hill DJ 1992 What is the role of growth hormone and related peptides in implantation and development of the embryo and foetus? Hormone Research 38 8-34.

Hojvat S, Baker G, Kirsteins L \& Lawrence AM 1982a Growth hormone $(\mathrm{GH})$ immunoreactivity in the rodent and primate CNS: distribution, characterization and presence post hypophysectomy. Brain Research 239 543-557.

Hojvat S, Emanuele NV, Baker G, Connick E, Kirsteins L \& Lawrence AM $1982 b$ Growth hormone (GH), thyroid stimulating hormone (TSH), and luteinizing hormone (LH)-like peptides in the rodent brain: non-parallel ontogenic development with pituitary counterparts. Brain Research 256 427-434.

Hojvat S, Emanuele NV, Kirsteins L \& Lawrence AM 1986 Impact of endocrine manipulations on brain-based rat growth hormone. Neuroendocrinology 44 335-360.

van Houten M, Posner BI \& Walsh RJ 1980 Radiographic identification of lactogen binding sites in rat median eminence using ${ }^{125}$ I-human growth hormone: evidence of a prolactin short-loop feedback site. Experimental Brain Research 38 455-461.

Hsu SM, Raine L \& Fanger H 1981 Use of avidin-peroxidase complex $(\mathrm{ABC})$ in immunoperoxidase techniques: a comparison between $\mathrm{ABC}$ and unlabeled antibody (PAP) procedures. Journal of Histochemistry and Cytochemistry 29 577-580.
Huang N, Cogburn LA, Agarwal SK, Marks HL \& Burnside J 1993 Overexpression of a truncated growth hormone receptor in the sex-linked dwarf chicken: evidence for a splice mutation. Molecular Endocrinology 7 1391-1398.

Hull KL, Thiagarajah A \& Harvey S 1996 Cellular localization of growth hormone receptor/binding proteins in immune tissue. Cell and Tissue Research 286 69-80.

Kuenzel WJ \& van Tienhoven A 1982 Nomenclature and location of avian hypothalamic nuclei and associated circumventricular organs. Journal of Comparative Neurology 207 293-313.

Lai Z, Emtner M, Roos P \& Nyberg F 1991 Characterization of putative growth hormone receptors in human choroid plexus. Brain Research 546 222-226.

Lechan RM, Nestler JL \& Molitch ME 1981 Immunohistochemical identification of a novel substance with growth hormone-like activity in rat brain. Endocrinology 109 1950-1962.

Lechan RM, Molitch ME \& Jackson IMD 1983 Distribution of immunoreactive human growth hormone-like material and thyrotropin-releasing hormone in the rat central nervous system: evidence for their coexistence in the same neurons. Endocrinology 112 877-884.

Lincoln DT, Sinowatz F, Temmim-Baker L, Baker HI, Kolle S \& Waters MJ 1998 Growth hormone receptor expression in the nucleus and cytoplasm of normal and neoplastic cells. Histochemistry and Cell Biology 109 141-159.

Lobie PE, Barnard R \& Waters MJ 1991 The nuclear growth hormone receptor binding protein: antigenic and physiochemical characterization. Journal of Biological Chemistry 26622645 22652.

Lobie PE, Garcia-Aragon J, Lincoln DT, Barnard R, Wilcox JN \& Waters MJ 1993 Localization and ontogeny of growth hormone receptor gene expression in the central nervous system. Developmental Brain Research 74 225-233.

Lobie PE, Wood JJ, Chen CM, Waters MJ \& Norstedt G 1994a Nuclear translocation and anchorage of the growth hormone receptor. Journal of Biological Chemistry 269 31735-31746.

Lobie PE, Mertani H, Morel G, Morales-Bustos O, Norstedt G \& Waters MJ $1994 b$ Receptor-mediated nuclear translocation of growth hormone. Journal of Biological Chemistry 26921330 21339.

Malamed S, Gibney JA, Cain LD, Perez FM \& Scanes CG 1993 Immunocytochemical studies of chicken somatotrophs and somatotroph granules before and after hatching. Cell and Tissue Research 272 369-374.

Mangurian LP, Lewis R \& Walsh RJ 1994 Placental lactogen binding sites in the pregnant rabbit choroid plexus. Journal of Anatomy 184 425-428.

Mol JA, van Gederen E, Rutteman GR \& Rijnbeck S 1996 New insights into the molecular mechanisms of progestin-induced proliferation of mammary epithelium: induction of the local biosynthesis of growth hormone $(\mathrm{GH})$ in the mammary glands of dogs, cats and humans. Journal of Steroid Biochemistry and Molecular Biology 57 67-71.

Murphy AE, Sanders EJ \& Harvey S 2000 Extrapituitary expression of pituitary hormones prior to pituitary differentiation during early embryogenesis. 8th Annual Western Perinatal Research Conference, Banff, Canada, p 41 (Abstract).

Noteborn HPJM, van Balen PP, Van der Gugten AA, Hart IC, Ebels I \& Salemink CA 1993 Presence of immunoreactive growth hormone and prolactin in the ovine pineal gland. Journal of Pineal Research 14 11-22.

Nyberg F \& Burman P 1996 Growth hormone and its receptors in the central nervous system - location and functional significance.

Hormone Research 45 18-22.

Porter TE 1997 Regulation of somatotroph differentiation during chicken embryonic development: a review. In Perspectives in Avian Endocrinology, pp 47-56. Eds S Harvey \& RJ Etches. Bristol: Society for Endocrinology. 
Porter TE, Couger GS, Dean CE \& Hargis BM 1995 Ontogeny of growth hormone $(\mathrm{GH})$-secreting cells during chicken embryonic development: initial somatotrophs are responsive to GH-releasing hormone. Endocrinology 136 1850-1856.

Radecki SV \& Scanes CG 1997 The hypothalamus-pituitary growth hormone (GH)-insulin-like growth factor (IGF) axis: coupling and uncoupling. In Perspectives in Avian Endocrinology, pp 119-133. Eds S Harvey \& RJ Etches. Bristol: Society for Endocrinology.

Ramesh R, Kuenzel WJ, Buntin JD \& Proudman JA 2000 Identification of growth hormone and prolactin containing neurons within the avian brain. Cell and Tissue Research 299 371-383.

Render CL, Hull KL \& Harvey S 1995 Neural expression of the pituitary GH gene. Journal of Endocrinology 147 413-422.

Rezvani I, Maddaigh VT, Collipp PJ, Thomas J \& Chen SY 1973 Kinetics of uptake and subcellular distribution of human growth hormone in liver slices. Biochemical Medicine 7 432-440.

Romanoff AL 1960 The Avian Embryo: Structural and Functional Development. New York: The MacMillan Company.

Sternberger LA 1979 The unlabeled antibody (PAP) method, introduction. Journal of Histochemistry and Cytochemistry 271657.

Tanaka M, Hayashida Y, Sakaguchi K, Ohkubo T, Wakita M, Hoshino S \& Nakashima K 1996 Growth hormone-independent expression of insulin-like growth factor-I messenger ribonucleic acid in extra-hepatic tissues of the chicken. Endocrinology 137 30-34.

Thornwall M, Chajlani V, LeGreves P \& Nyberg F 1995 Detection of growth hormone receptor mRNA in an ovine choroid plexus epithelium cell line. Biochemical and Biophysical Research Communications 217 349-353.

Vanderpooten A, Huybrechts LM, Decuypere E \& Kuhn ER 1991 Differences in hepatic growth hormone receptor binding during development of normal and dwarf chickens. Reproduction, Nutrition, Development 31 47-55.

Vanderpooten A, Janssens W, Buyse J, Leenstra F, Berghman L, Decuypere E \& Kuhn ER 1992 Ontogenic study of the hepatic growth hormone $(\mathrm{GH})$ receptor in chickens selected for a good feed conversion (FC) and a fast growth (GR). Domestic Animal Endocrinology 10 199-206.

Wride MA 1996 Cellular and molecular features of lens differentiation: a review of recent advances. Differentiation 61 77-93.

Wright GM 1986 Immunocytochemical demonstration of growth hormone, prolactin and somatostatin-like immunoreactivities in the brain of larval, young adult and upstream migrant adult sea lamprey, Petromyzon marinus. Cell and Tissue Research 246 23-31.

Yang BY, Greene M \& Chen TT 1999 Early embryonic expression of the growth hormone family protein genes in the developing rainbow trout, Onchorynchus mykius. Molecular and Reproductive Development 53 127-134.

Received 22 January 2001

Accepted 7 February 2001 